\title{
Social Protection and Graduation through Sustainable Employment*
}

\author{
Anna McCord and Rachel Slater
}

Abstract This article explores the role of social protection in contributing to sustainable employment in the context of the broader graduation debate. Many efforts to achieve graduation focus on the household or community level: helping households reach a certain asset and productivity level at which they are able to survive, and perhaps prosper, without support from cash transfer programmes; building assets at community level to provide public goods that increase economic productivity; and making communities more resilient to specific shocks and stress (for example, by supporting community soil and water conservation). However, it remains critical to focus on broader questions of employment and labour markets to understand how social protection programme design might impact on recipient households' wider job prospects, and to recognise that the feasibility and scale of graduation depend on wider factors such as labour demand and labour market structures, as well as on improving individual capacity and productivity.

\section{Introduction}

Recent data about employment and poverty provide insights that may surprise many working in social protection. In 2013 an estimated 839 million workers globally were living in poverty. Of these, 375 million experienced 'extreme' poverty (living on less than US $\$ 1.25$ a day) and 464 million experienced 'moderate' poverty (living on between US\$1.25 and US $\$ 2$ a day) (ILO 2014a). In sub-Saharan Africa and South Asia the working poor comprise two-thirds of the employed, with the extreme working poor accounting for 42 and 26 per cent respectively. Altogether, one-third of the developing world's workforce lives in poverty (ILO 2013). An additional 661 million 'near poor' workers, or one quarter of the developing world's workforce, live on US\$2-4 a day. Overall, 58 per cent of the developing world's workforce remained poor or near the poverty line in 2011 (ILO 2013, drawing on Kapsos and Bourmpoula 2013).

At the same time, where there is economic growth in low- and middle-income countries, the associated increase in employment is limited and of poor quality, often due partly to ongoing dependence on minerals and agriculture. Between 2007 and 2011, there was limited structural change in labour markets as job reallocation across sectors slowed. At the same time, employment in low-productivity agriculture fell and employment in industry and services rose, but at a significantly slower rate than prior to the 2008-09 food, fuel and financial crisis.

So, in the poorest regions, the challenge in the labour market is to improve the quality of lowproductivity and poorly remunerated employment rather than solely addressing the lack of employment, per se. This is especially true given the slow nature of structural transformation and the continuing dominance of employment in the agricultural and own-account sectors (self-employment such as subsistence agriculture or informal petty trade) which are characterised by poor quality employment (Filmer and Fox 2014).

In this context the aspiration has emerged that social protection can play a role in promoting productivity and creating much needed sustainable employment, and it is this challenge which social protection is charged with in many social protection programmes in low-income countries. In many places it remains an aspiration, the evidence base is thin, and there is little programming guidance for those seeking to use social protection to support sustainable 
Figure 1 Dimensions of sustainable employment

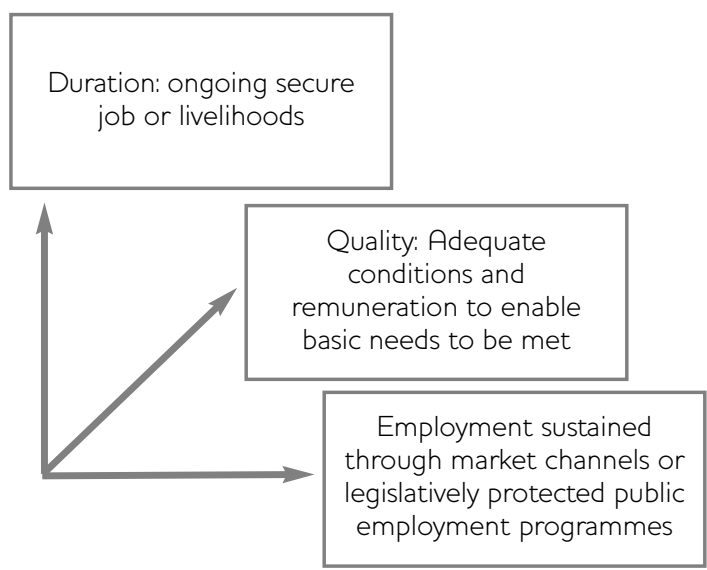

Source Authors' own.

employment. Furthermore, in recent years social protection and labour appear to have become more distant, rather than closer, in the policies and programmes of major social protection donors. For example, whilst the 2005

Department for International Development (DFID) definition of social protection included labour standards, in practice DFID social protection programmes rarely, if ever, focus on the quality of labour, regulation or standards. Similarly, in the World Bank, whilst historically social protection and labour have been housed together at a policy level, the links between them have weakened over the years in programming. Thus, whilst aspirations are high, it is not clear that policymakers and programmers are equipped with the knowledge and programme design expertise to make connections between social protection and sustainable employment. This article seeks to address the knowledge part of this gap. It aims to contribute to a better, evidence-based understanding of the role that social protection programmes can and do play in supporting sustainable employment.

The remainder of the article proceeds as follows. We begin by defining social protection and key concepts and terms related to sustainable employment. We then identify the main ways, in theory and in practice, by which social protection programmes might support sustainable employment in three cases. We do this with reference to three types of social protection programmes: basic cash transfer programmes, public works programmes and livelihoods programmes that incorporate a social transfer.
The conclusions suggest what the implications might be for policymakers and programmes in social protection.

\section{Definitions}

This article focuses on that part of social protection that provides cash or in-kind transfers to compensate for lack of, or insufficient, income. Whilst social insurance (for example, contributory pensions which insure against loss of productive capacity in old age, or unemployment benefits) is a critical part of the link between social protection and employment, this article focuses on social assistance - or transfers. This is because social insurance is minimal in most lowand middle-income countries and where it is in place it tends to be concentrated among the less poor in formal sector employment.

The term employment is taken to include paid wage labour opportunities in the formal and informal economy, as well as self-employment in 'own-account work' including agricultural smallholdings, microenterprises and other activities, following the definition of 'jobs' as set out in the World Development Report 2013 (World Bank 2012). The quality of employment is determined by the type of job, working conditions, remuneration, the contract, benefits, and safety and security at work.

Sustainable employment may be defined as having three axes, comprising employment which is ongoing and secure; offers adequate remuneration and working conditions; and is provided by the economy rather than external interventions (such as aid), as illustrated in Figure 1. In this definition we acknowledge that the focus on market-based employment in the third axis is not clear-cut. This is because statesponsored employment programmes can potentially be sustainable and significant in scale, with a prominent example being India's national public employment programme, the Mahatma Gandhi National Rural Employment Guarantee Scheme (MGNREGS) which is legislatively underpinned.

\section{Theories of change for social protection and sustainable employment}

Theoretically, social protection programmes can contribute to sustainable employment by overcoming both supply- and demand-side barriers to employment. 
The key supply-side barriers (formal and informal, wage labour and own-production) comprise a range of individual characteristics relating to economic, social and cultural factors. They can be summarised as: lack of skills, work experience and/or life skills (job-seeking and personal); lack of capital for job search; domestic responsibilities and high dependency ratios; gender, disability, ethnicity and social identity; and lack of land, capital or assets. These characteristics limit access to both wage and selfemployment by constraining the productivity and diversity of livelihoods in which the working poor engage. The dominant theory of change (TOC) underlying much current social protection programming is that transfers will enable recipients to overcome some of these barriers. This includes guaranteeing a transfer at times of need, and thereby potentially easing constraints to risk-taking behaviour which might promote livelihoods diversification and entrepreneurship. Social protection can enable beneficiaries to overcome capital barriers to wage and ownaccount employment, for example, by enabling beneficiaries to fund education, training or travel to seek work; and can help to improve the quality of labour supply and overcome skills barriers to employment, for example by promoting skills and work experience within Public Employment Programmes (PEPs).

Supply-side barriers to employment relate to individual characteristics, but frequently the barriers lie within the labour market, taking the form of seasonal or chronic lack of demand, which may be exacerbated by location. In such contexts labour markets cannot absorb all jobseekers, even if they are skilled and able to work. In theory, social protection can play a role in directly and indirectly affecting these demandside constraints through direct employment creation and indirect or spillover effects.

Directly, social protection can play a role in complementing market-based employment by creating additional non-market employment opportunities - usually sponsored by the state. Typically, such PEPs offer cash or food in return for labour inputs. Social protection provision can also have spillover effects that extend beyond the immediate household income benefit. Wages and transfers can stimulate the local economy (promoting local demand for goods and services) and potentially have multiplier effects on local economic development which extend beyond primary recipients and result in increased labour demand. The assets created through PEPs also have the potential to contribute to spillover effects that impact on local economic development. These assets can impact on local economic development inasmuch as the infrastructure created can directly address constraints to production. They can: increase land under production; enhance productivity by reducing environmental degradation, promote soil and water conservation/irrigation; mitigate disaster risk; and promote local markets by improving economic integration (for example, where the assets created are roads or bridges).

Some of these effects can be achieved through simple cash transfer programmes, whilst others require more complex programming - for example, public works or livelihoods programmes where a social transfer is one of a suite of programme components. Social protection is often accompanied by complementary programming in the areas of training, microcredit, savings, and so on. In the next section we examine the evidence on three types of social protection programmes: simple cash transfers; public works programmes; and livelihoods programmes, and explore the extent to which they address the barriers identified above.

\section{Cash transfer programmes and sustainable employment}

Despite the limitations of available impact evaluations and research, it is possible to identify challenges to the assumptions about the role of social protection in relieving supply- and demandside constraints to sustainable employment.

Evidence indicates that cash transfer provision can reduce supply-side barriers to sustainable employment and potentially also increase local demand through spillover effects. These effects are to a large degree determined by transfer design considerations, most notably the value of the transfer. They are likely to vary depending on whether labour-constrained households are included or excluded from provision. In the latter case the effects are primarily limited to indirect spillover benefits.

Evidence consistently demonstrates that cash transfers can create positive outcomes for ownaccount activities and wage employment. However, this depends on: (1) the sufficiency of 
the transfer; and (2) the economic context. Cash transfer provision increases labour market participation, particularly among women, by reducing financial barriers to participation and job search. In Brazil, recipients of the Bolsa Escola and Bolsa Família programmes used increased income to finance transport and alternative childcare. In Namibia, provision was followed by increased labour force activity by women and increased job-search activity by men and women. In South Africa, the labour force participation rate of those receiving cash transfers increased by 13 per cent to 17 per cent compared to those in similar households not receiving transfers, again with the greatest increase for women (Standing 2012). Similarly, receipt of the old-age pension in South Africa had a significant positive impact on labour supply and job search (Posel, Fairburn and Lund 2006).

Where sufficient to compensate for lost income, transfers have also reduced labour market participation among those not of conventional working age, notably children and the elderly. Lam, Leibbrandt and Ranchhod (2005), for example, identify labour market withdrawal among the elderly driven by pension receipt in South Africa.

Cash transfers have also been found to impact directly on livelihoods activity. Receipt of transfer income has been found in some cases to result in recipient households hiring additional labour, thereby increasing the productivity of land and assets previously underused, and simultaneously promoting labour demand (DFID 2011). The Madhya Pradesh Unconditional Cash Transfer and Tribal Village Unconditional Cash Transfer pilots in India have also had significant impacts on livelihoods and wage labour (Standing 2013). In addition to productivity gains, the pilots indicated that cash transfer receipt enabled changes in the terms of labour market engagement, namely:

a shift from casual wage labor to more ownaccount (self-employed) farming and business activity, with less distress-driven outmigration. Women gained more than men... There was an unanticipated reduction in bonded labor (naukar, gwala). This has huge positive implications for local development and equity (Standing $i b i d$.).
Access to transfers enabled recipients to shift their location within a highly segmented labour force, moving out of the most exploitative forms of employment and into potentially more sustainable forms. Here, transfer receipt promoted movement out of casual wage labour (where households were sometimes trapped in bonded labour or caught in interlocked markets for labour, land and credit) and into own-account activities. It is not clear whether the effects will be sustainable if the cash transfer is withdrawn.

Less well attested is how far cash transfers support entrepreneurship by providing a safety net, enabling recipients to develop skills and to take entrepreneurial risks (Kaufmann 2010); nor the circumstances in which precarious entrepreneurial activity can become sustainable employment. Evidence suggests that those developing micro-survivalist businesses such as petty trading may fall back into their economic and livelihood status quo ante once the transfer ends (Ndoto and Macun 2005). Overall, the impact of such interventions on sustained employment gains appears to depend on a number of factors, including:

- value of the transfer relative to the depth of poverty of receiving households, since a greater share of the transfer is directly consumed rather than used for entrepreneurial purposes where it accounts for a smaller proportion of the poverty gap (Devereux 2002);

- duration of provision, which is neither predictable nor sustained in many low-income contexts;

- concentration of provision (the number of beneficiaries in a location);

- nature of the local economy and its ability to accommodate the additional goods and services provided by new suppliers.

\section{Public employment and sustainable employment}

Public Employment Programmes (PEPs), also known as public works programmes, food/cash for work and food for assets, provide non-market employment sponsored by governments or donors, and vary substantially. Some entail mass direct job creation and provide ongoing or cyclical employment, whilst others provide highly rationed temporary employment. The former is exemplified by the demand-driven Mahatma 
Gandhi National Rural Employment Guarantee Scheme (MGNREGS) in India, which provides up to 100 days' employment to over 50 million workers each year on an ongoing basis and by the Productive Safety Nets Programme (PSNP) in Ethiopia, which provides seasonal employment benefiting an average of 7 million people a year. Rationed temporary approaches are exemplified by the many PEPs providing one-off employment opportunities in sub-Saharan Africa and South and Southeastern Asian countries (McCord 2013).

With the PSNP, evidence exists of livelihoods benefit and increased resilience, in terms of returns to production, although only after multiple years of employment combined with complementary interventions. This outcome conforms to all three axes of sustainable employment, inasmuch as the intervention provides:

- cyclical and reliable PEP employment;

- adequate PEP returns to labour;

- limited market-based livelihoods improvements, relating to improved returns to own-account activity (Berhane et al. 2011), although not, for most farmers, resulting in 'sustainable graduation' (Devereux, forthcoming).

Over the short term, and where the PSNP has been implemented with only limited complementary interventions, the impact on livelihoods has not been significant (Berhane $e t$ al. 2011) and the primary gains relate only to direct PEP employment and income - the first two axes of sustainable employment. However, the programme does not result in the creation of sustainable employment since ongoing PEP employment relies on continued state and donor sponsorship (which unlike India's Mahatma Gandhi National Rural Employment Guarantee Act (MGNREGA) is not legislatively guaranteed), rather than market-based demand. Similar findings are emerging from the Vision 2020 Umurenge Programme (VUP) in Rwanda, where ongoing support is required to ensure sustained productivity gains, and the programme is not generating self-sustaining employment outcomes independently.

Interestingly, the largest of all PEPs, the Indian MGNREGS, is designed to provide ongoing state-sponsored employment without seeking to stimulate market-based sustainable employment outcomes. As such it satisfies the first two axes of sustainable employment, and arguably, the third, because of the legislated nature of the programme. MGNREGS provides an entitlement to work where provision is based on an Act rather than a project basis and, hence, provides work in an ongoing and sustainable way. Furthermore, the scale of the programme means that it has the potential to affect the quality of existing marketbased employment and improve the terms of employment (Basu 2011).

However, the MGNREGS and the PSNP are exceptional in providing employment to approximately 5 and 15 per cent of respective national labour forces and offering ongoing or repeated employment. Few other developing country programmes provide similar coverage or duration. PEPs providing short-term and one-off support may address temporary labour market disruptions effectively but do not stimulate sustainable employment outcomes or respond to the challenge of working poverty (Slater and McCord 2009). Hence, PEP benefits are limited beyond immediate benefits accruing from wage receipt and offer few opportunities for the accumulation of assets that can overcome supplyside obstacles to employment. The low wages paid under many schemes in many cases replicate poor labour returns in the open labour market, thereby contributing to, rather than overcoming, extreme poverty among the working poor.

There is little evidence to support the assertion that short-term PEP employment provides work experience and skills training that can promote labour market engagement. Without increased demand for low-skilled labour, and with few skills transfers occurring, there is a risk that PEPs may result in the substitution of one set of workers for another, rather than aggregate increases in employment (Harvey 2000). The limited evidence suggests that PEPs do not have a sustained impact on post-PEP employment (see Ndoto and Macun 2005) and that PEP income is primarily consumed due to low wage levels (McCord 2003; Devereux 2002). Microenterprise outcomes tend to be commensurately small-scale and survivalist in nature and not sustained after temporary employment and wage transfer. The more effectively employment targets the poorest, the lower the likelihood of a 
restricted wage resulting in sustainable livelihoods or wage employment gains.

Inasmuch as PEPs provide additional work opportunities, they can serve to ameliorate underemployment, increasing the hours of paid labour available (see, for example, Bandiera et al. 2013 relating to the Targeting the Ultra Poor Programme in Bangladesh).

The assets created through PEPs can also improve agricultural productivity, either of beneficiary households or the wider community, and stimulate increased labour demand, although there is little evidence to show the extent of such productivity gains or the distribution of direct and indirect employment opportunities resulting from them. This is an area which is significantly under-explored, particularly in terms of medium-term (sustainable) rather than short-term outcomes.

\section{Returns to labour}

PEPs have the potential to impact on returns to labour and hence affect the quality of wage employment. Where a PEP wage is set below market wages to ration access, sustained employment gains are unlikely. However, when set above market wage levels and in cases where significant levels of employment relative to labour supply are provided through the programme, the PEP wage can create a reservation wage that drives up market wage rates, creating a wage floor. This has been documented in relation to the MGNREGS by Basu (2011). This outcome has been perceived by some as negative in terms of labour market distortion (del Ninno, Subbarao and Milazzo 2009), or more positively as a response to adverse terms of employment (McCord 2013). Whichever the perspective, it is important to note that the returns to labour are improved; on one hand as an indirect consequence of the impact of mass PEP employment on market rates, and on the other by enabling a limited number of workers to withdraw their labour from adverse marketbased employment in favour of sponsored employment.

However, such wage effects are only likely when the scale of operation is significant relative to local labour demand, and where there is concentrated PEP employment such that some form of collective bargaining is possible (Gaiha
1997). Wage effects also depend on other factors, including the timing of PEP employment relative to periods of high agricultural demand, whether the PEP takes in primarily employed or unemployed workers and the prevailing terms of employment (for example, debt-bonded labour).

\section{Livelihoods programming and graduation}

In a number of 'productive' social protection programmes, transfers are combined with complementary interventions to promote ownaccount productivity or wage employment in the guise of a livelihoods programme. Typical examples include the Chars Livelihoods Programme (CLP) and Challenging the Frontiers of Poverty Reduction (CFPR) programme in Bangladesh, which have been replicated elsewhere (see, for example, CGAP 2011). Complementary interventions include: agricultural extension; microfinance and financial inclusion; lump sum/asset provision; and active labour market policies. The evidence relating these to sustainable employment outcomes is summarised here.

\section{Agricultural extension}

Results vary and depend on programme design attributes, the socioeconomic characteristics of recipient households and the broader sociopolitical and economic context.

Complementary programming was central to the design of the PSNP in Ethiopia. In the first phase, the provision of agricultural extension services was inadequate and households received only limited support. This is indicative of a challenge shared by many social protection programmes aiming to promote productivity: the limited reach of agricultural and development programming in many low-income countries, and the often low levels of funding and human resources allocated to the agricultural sector, following several decades of underinvestment (Filmer and Fox 2014). The second phase of the PSNP included a greater emphasis on supporting the provision of complementary programming, in the form of the Household Asset Building Programme (van Uffelen 2013), as well as agricultural extension. Later evidence indicates that complementary services can play a role in enhancing the food security impact of public works employment (although not necessarily the impact on sustainable employment), only when PEP employment is provided over an extended period (Berhane et al. 2011). 


\section{Microfinance and financial inclusion}

The promotion of microfinance and financial inclusion as mechanisms to promote livelihoods benefits and 'graduation' out of poverty are key components of many social protection initiatives. Transfer receipt enables regular saving and financial inclusion promotes savings behaviour, thus assisting participants to overcome financial barriers to sustainable employment.

In the CFPR programme in Bangladesh, the 'graduation model' comprises cash transfers for consumption alongside microfinance inputs, skills training and provision of a lump sum or inkind asset transfer (CGAP 2011). Of more than 300,000 households receiving support, 75 per cent were estimated to have become 'food secure and managing sustainable economic activities' (ibid.). However, the extent to which beneficiaries of such programmes have attained sustainable employment outcomes is not demonstrated in the evidence.

\section{Lump sum provision for asset purchase}

The provision of a cash transfer alongside a lump sum for asset purchase recognises that lump sums are unlikely to be used for investment unless resources are provided to meet ongoing consumption needs. CLP provided funds for the purchase of an asset (such as livestock), technical support (such as husbandry and veterinary requirements) and a small monthly stipend to prevent the sale of the asset before it became productive (for example, providing milk and calves) to meet immediate consumption needs (Farrington and Slater 2009; see also Pritchard, Kenward and Hannan, this IDS Bulletin). Evidence suggests that such programmes have the potential to contribute to sustainable employment but are resource-intensive, raising issues of feasibility in many countries.

Altogether, combinations of programme components can have significant impacts on labour opportunities. A recent study into the Targeting the Ultra Poor (TUP) programme component of the GFPR (Bandiera et al. 2013) suggested that in line with employment preferences, the extreme poor changed their occupational status to engage in more productive livelihoods when binding capital constraints were removed (in the case of TUP) through an asset transfer and associated training). What we know less about is the extent to which these impacts are sustained once the transfer element of livelihoods programmes ends.

\section{Programme design features and wider spillover effects}

Whilst limited, available evidence points to broad conditions under which transfers are more likely to result in sustainable employment outcomes. Six key conditioning factors or enablers/constrainers can be identified, relating to programme, beneficiary, community and market characteristics, namely: targeting, transfer value, transfer duration, transfer reliability, scale of coverage and integration with other developmental programmes. Together, these determine the extent to which successful transition into sustainable employment (graduation) can be anticipated (Mathers and Slater 2014; Sabates-Wheeler and Devereux 2011; Huda et al. 2011).

\subsection{Effective targeting}

Different targeting approaches have different impacts on sustainable employment. Trade-offs exist between targeting that maximises poverty reduction and targeting that maximises sustainable employment outcomes. Targeting particular demographic groups, such as elderly or young people, is likely to directly address supply-side barriers to employment when recipient households have working-age members. Indirectly, these approaches may stimulate local aggregate demand, including hiring labour on the part of labour-constrained households. Targeting poor working-age recipients has potential for directly supporting own-account employment by building productive asset portfolios at household level that increase productivity. Targeting specific marginalised groups may improve access to labour markets by changing social status and exclusion, though there is little evidence for this.

\subsection{Transfer value}

Small value transfers have little impact on sustainable employment. They are mainly used for consumption and are rarely sufficient to enable significant asset accumulation or investment in more productive activities (Devereux 2002; Carter and Barrett 2006). Impacts on local aggregate demand, and therefore labour, are limited. 


\subsection{Transfer duration}

Duration of transfer receipt also has an impact on the potential for accumulation and investment, and on recipient behaviour. Ongoing transfer receipt is necessary to achieve capital accumulation (or sufficient human capital to overcome education-related barriers to employment). The longer the duration of the transfer, the greater the potential for sustainable employment gains (Berhane et al. 2011). Ongoing inputs are also necessary for spillover effects to be significant and sustained.

\subsection{Transfer reliability}

When transfers are predictable and regular they enable recipients to plan their expenditure and use it more productively. They also allow households to access credit which is frequently used to allow job search and migration to seek more secure and better paid work. If unpaid for many months, transfers are likely to be used like lump sum 'windfall' transfers, since their primary function of consumption smoothing is undermined (Farrington and Slater 2009). Irregular and delayed transfers can undermine prospects for effective microfinance participation, or local saving and borrowing activities. This can even result in increased levels of indebtedness if anticipated transfer flows, used as security for loans, are delayed or not delivered.

\subsection{Scale of coverage}

The scale and concentration of social protection coverage are critical determinants of impacts on demand for goods, services and labour. A critical mass of resources is required in a local economy for a sustained period to stimulate rural development and improved employment. Such effects have been found in some programmes for example, with the Progresa programme in Mexico (Barrientos and Sabates-Wheeler 2006) but where coverage and transfer value are low, the impact is unlikely to be significant.

\subsection{Integration with other developmental programmes}

The final critical factor is whether social protection complements other social, economic and agricultural policies and interventions. Social protection transfers can only address a limited set of financial barriers to labour supply and demand, with minimal impact on the structural determinants of under- and unemployment and related issues of social exclusion. Complementary interventions are required for a cash transfer to contribute to the promotion of sustainable employment.

\section{Spillover effects}

Broader spillover effects of social protection on sustainable employment occur primarily through recipients' increased demand for goods and services (DFID 2011), including explicit increases in labour demand arising from transfer receipt, irrespective of recipient characteristics:

These multipliers apply equally to transfers given to economically inactive groups (e.g. social pensions or child support grants) as to transfers given to small farmers, though the synergies with agriculture are likely to be higher if the recipients are farmers, who will spend some of this incremental income on farming (Sabates-Wheeler, Devereux and Guenther 2009).

The magnitude and distributional impacts of multipliers are contingent on factors including the nature of the local economy and expenditure patterns of groups receiving transfers. SabatesWheeler et al. (2009) conclude that:
Although the macro-economic benefits claimed for cash transfers are based on limited empirical findings, and the evidence to date is ambivalent (Devereux and Coll- Black 2007), there is sound evidence from Africa and Latin America for localised multiplier effects of social transfers.

This evidence includes documented spillover benefits of the Oportunidades cash transfer programme in Mexico, beyond direct recipients, resulting in consumption increases throughout programme areas, among both those in receipt and those not in receipt (Barrientos and SabatesWheeler 2006). The evidence also identifies regional multiplier effects resulting from cash transfer programming in Malawi that stimulate local commerce and trading activity (Davies and Davey 2008), although the extent to which benefits are sustained after transfer receipt is not well documented.

Whilst the evidence base remains thin - in part because there are no well-developed, robust methodologies to monitor these effects and explore the relationship between social protection and sustainable employment - current 
initiatives such as the Food and Agriculture Organization's (FAO) 'Protection to Production' study $^{2}$ may yield insights in the coming year (see Daidone et al., this IDS Bulletin).

\section{Conclusions}

This article has explored the extent to which social protection interventions may impact on supply and demand barriers to sustainable employment. Social protection transfers can promote sustainable employment directly by reducing supply-side barriers to employment; indirectly by stimulating labour demand as a result of increased demand for goods and services; and by promoting aggregate employment through sponsored work programmes.

A number of key design features that have the potential to contribute to sustainable employment across a range of social protection instruments have been identified in this article. If social protection programming can respond to these six enabling factors, then the potential for social protection provision to result in sustainable employment will be enhanced. If not, prospects for even direct welfare benefits are limited, and secondary employment-related effects are unlikely. It is important to note that together these six factors reflect good practice across social protection programmes in a very broad sense and are shared across the three

\section{Notes}

* This article is based on research funded by the Department of Foreign Affairs and Trade (DFAT). The views and opinions expressed in this document are those of the authors and do not necessarily reflect the views of DFAT or the Australian government.

1 'Only a small minority of unemployed workers in many developing countries can expect to

\section{References}

Bandiera, O.; Burgess, R.; Das, N.; Gulesci, S.; Rasul, I. and Sulaiman, M. (2013) Can Basic Entrepreneurship Transform the Economic Lives of the Poor?, IZA Discussion Paper 7386, Bonn: Institute for the Study of Labor

Barrientos, A. and Sabates-Wheeler, R. (2006) Local Economy Effects of Social Transfers, Final Report for DFID, Brighton: IDS

Basu, A.K. (2011) Impact of Rural Employment Guarantee Schemes on Seasonal Labor Markets: Optimum Compensation and Workers' Welfare, IZA social protection instruments discussed here. There is no trade-off between the core objectives of social protection (tackling poverty and vulnerability) and the objective of sustainable employment. Rather, what is good for social protection in general, is also good for achieving the best sustainable employment outcomes.

The major question arising from this review is the extent to which the current scale and coverage of programmes, and their predominant focus on supporting self- or own-account employment, are enough to tackle the dominant barriers to sustainable employment. Current social protection experience and practice remains focused on tackling supply-side constraints (often by attempting to turn the recipients of social transfers into entrepreneurs) and far less attention is paid to the demand side, which would entail a rather more ambitious agenda of job creation, and the quality of work created. Ultimately, from a sustainable employment perspective, the preoccupations of most social protection expenditures - with their focus on creating entrepreneurs (own-account workers) rather than addressing challenges relating to the availability and quality of employment - appear rather out of kilter with the nature of much poverty in developing countries, and especially the challenge of underemployment, and the alarmingly high and largely unrecognised scale of working poverty.

receive any kind of cash unemployment protection benefits [contributory or noncontributory]; 7.2 per cent of unemployed workers in Asia and the Pacific, 4.6 per cent in Latin America and the Caribbean, and less than 3 per cent in the Middle East, North Africa and Sub-Saharan Africa' ILO (2014b: 36).

2 See www.fao.org/economic/ptop/publications/ reports/en.

Discussion Paper 5701, Bonn: Institute for the Study of Labor

Berhane, G.; Hoddinott, J.; Kumar, N.; Seyoun Taffesse, A.; Diressie, M.; Yohannes, Y.; Sabates-Wheeler, R.; Handino, M.; Lind, J.; Tefera, M. and Sima, F. (2011) Evaluation of Ethiopia's Food Security Program: Documenting Progress in the Implementation of the Productive Safety Nets Programme and the Household Asset Building Programme, Brighton: IDS

Carter, M.R. and Barrett, C.B. (2006) 'The Economics of Poverty Traps and Persistent 
Poverty: An Asset-based Approach', Journal of Development Studies 42.2: 178-99

CGAP (2011) Reaching the Poorest: Lessons from the Graduation Model, Focus Note 69, Washington DC: Consultative Group to Assist the Poor

Davies, S. and Davey, J. (2008) 'A Regional Multiplier Approach to Estimating the Impact of Cash Transfers on the Market: The Case of Cash Transfers in Rural Malawi', Development Policy Review 26.1: 91-111

del Ninno, G.; Subbarao, K. and Milazzo, A. (2009) How to Make Public Works Work: A Review of the Experience, SP Discussion Paper 0905, Washington DC: World Bank

Devereux, S. (forthcoming) 'Do "Graduation" Programmes Work for Africa's Poorest?', in D. Hulme and D. Lawson (eds), What Works for the Poorest in Africa, London: Palgrave Macmillan

Devereux, S. (2002) 'Can Social Safety Nets Reduce Chronic Poverty?', Development Policy Review 20.5: 657-75

Devereux, S. and Coll-Black, S. (2007) Review of Evidence and Evidence Gaps on the Effectiveness and Impacts of DFID-supported Pilot Social Transfer Schemes, DFID Social Transfers Evaluation, Brighton: IDS

DFID (2011) Cash Transfers, Evidence Paper, London: Department for International Development

Farrington, J. and Slater, R. (2009) Lump Sum Cash Transfers in Developmental and Post-emergency Contexts: How Well have they Performed?, Overseas Development Institute Research Report, London: Overseas Development Institute Filmer, D. and Fox, L. (2014) Overview: Youth Employment in Sub-Saharan Africa, Washington DC: World Bank

Gaiha, R. (1997) 'Do Rural Public Works Influence Agricultural Wages? The Case of the Employment Guarantee Scheme in India', Oxford Agrarian Studies 25.3: 301-14

Harvey, P. (2000) 'Direct Job Creation', in A.W. Warner, M. Forstater and S.M. Rosen (eds), Commitment to Full Employment: The Economics and Social Policy of William S. Vickrey, Armonk NY: M.E. Sharpe

Huda, K.; Kaur, S.; Sengupta, A. and Lamhauge, N. (2011) Graduating Out of Extreme Poverty: Who Succeeds?, BDI Research Brief 05, August, BRAC Development Institute (BDI)

ILO (2014a) Global Employment Trends 2014. Risk of a Jobless Recovery?, Geneva: International Labour Organization
ILO (2014b) World Social Protection Report 2014/15, Geneva: International Labour Organization

ILO (2013) Global Employment Trends 2013: Recovering from a Second Jobs Dip, Geneva: International Labour Organization

Kapsos, S. and Bourmpoula, E. (2013) Employment and Economic Class in the Developing World, ILO Research Paper 6, Geneva: International Labour Organization

Kaufmann, J. (2010) 'BIG Hopes, BIG Questions: Namibia's Basic Income Grant. Public Administration', Journal of Civil Society and Social Transformation 1: 38-47

Lam, D.; Leibbrandt, M. and Ranchhod, V. (2005) Labour Force Withdrawal of the Elderly in South Africa, CSSR Working Paper 118, Cape Town: Centre for Social Science Research, University of Cape Town

Mathers, N. and Slater, R. (2014) Social Protection and Growth: Research Synthesis, London:

Overseas Development Institute

McCord, A. (2013) Public Works and Social Protection in Sub-Saharan Africa. Do Public Works Work for the Poor?, Cape Town/Tokyo: Juta/UNU Press

McCord, A. (2003) An Overview of the Performance and Potential of Public Works Programmes in South Africa, SALDRU/CSSR, Working Paper 49, Cape Town: Southern Africa Labour and Development Research Unit/Centre for Social Science Research, University of Cape Town

Ndoto, M. and Macun, I. (2005) 'World Wide Fund for Nature Rapid Socio-economic Survey of Working for Wetlands', unpublished report, Cape Town: CASE

Posel, D.; Fairburn, J. and Lund, F. (2006)

'Labour Migration and Households: A Reconsideration of the Effects of the Social Pension on Labour Supply, South Africa', Economic Modelling 23.5: 836-53

Sabates-Wheeler, R. and Devereux, S. (2011) Transforming Livelihoods for Resilient Futures: How to Facilitate Graduation in Social Protection Programmes, Working Paper 023, Brighton: Future Agricultures Consortium

Sabates-Wheeler, R.; Devereux, S. and Guenther, B. (2009) Building Synergies between Social Protection and Smallholder Agricultural Policies, Working Paper 06, Brighton: Future Agricultures Consortium

Slater, R. and McCord, A. (2009) Social Protection, Rural Development and Food Security: Issues Paper on the Role of Social Protection in Rural Development, London: Overseas Development Institute 
Standing, G. (2013) 'India's Experiment in Basic Income Grants', Global Dialogue: Newsletter for the International Sociological Association 3.5

Standing, G. (2012) Cash Transfers: A Review of the Issues in India, Social Policy Working Paper Series 1, New Delhi: UNICEF India van Uffelen, J. (2013) 'Social Protection in Situations of Chronic Food Insecurity and
Poverty: Lessons from Different Models and Implications for Ethiopia', in D. Rahmato, A. Pankhurst and J. van Uffelen (eds), Food Security, Safety Nets and Social Protection in Ethiopia, Addis Ababa: Forum for Social Studies: 5-40

World Bank (2012) World Development Report 2013: Jobs, Washington DC: World Bank 